\title{
Recurrent intra-cranial granulomata presenting as space-occupying lesions in a patient with common variable immunodeficiency
}

\author{
S.A. Misbah ${ }^{1}$, G.P. Spickett ${ }^{1}$, M.M. Esiri², J.T. Hughes², W.B. Matthews ${ }^{3}$, \\ R.A. Thompson ${ }^{4}$ and H.M. Chapel ${ }^{1}$
}

Departments of ${ }^{1}$ Immunology, ${ }^{2}$ Neuropathology, ${ }^{3}$ Clinical Neurology, John Radcliffe Hospital and Radcliffe Infirmary, Oxford, and ${ }^{4}$ Regional Immunology Department, East Birmingham Hospital, UK

\begin{abstract}
Summary: A patient with profound panhypogammaglobulinaemia due to common variable immunodeficiency developed two discrete intra-cranial space-occupying lesions, 10 years apart, requiring craniotomy. Histological examination revealed the intra-cranial masses to be granulomata of unknown aetiology on both occasions.
\end{abstract}

\section{Introduction}

The occurrence of epithelioid granulomata in patients with common variable immunodeficiency (CVI) is well recognized. ${ }^{1}$ Granulomata have been described in many sites including the skin, chest, liver, spleen, lymph nodes and intestines. We are unaware of any previous reports of cerebral granulomata in CVI and describe a patient with CVI who presented with two space-occupying lesions separated by an interval of 10 years, each due to a discrete cerebral granuloma.

\section{Case report}

A Caucasian female first presented in 1972 at the age of 11 years to another hospital with right-sided facial twitching. An electroencephalogram showed focal spike discharges during overbreathing and a diagnosis of epilepsy was made. Treatment with sulthiame was commenced. Two years later rightsided focal seizures associated with behavioural problems prompted referral to the neurology department. Examination revealed bilateral papilloedema and carotid angiography suggested the presence of a left frontal space-occupying lesion. At craniotomy, a medium-sized frontal tumour was removed. Histopathological examination revealed a localized granulomatous mass consisting of

Correspondence: S.A. Misbah, M.R.C.P. Accepted: 23 September 1991 plasma cells, macrophages and many multi-nucleated giant cells. Gram stain for bacteria, ZiehlNeilsen stain for acid fast bacilli and culture were all negative. Following craniotomy, considerable clinical improvement was noted with residual periodic emotional lability, attributed to loss of frontal inhibition. Phenytoin was commenced post-operatively and continued until 1979.

In 1984 she was referred back with a 3 week history of behavioural problems, diplopia on distant gaze and blurred vision. Bilateral papilloedema was again noted and a cranial computed tomographic (CT) scan showed a large, right-sided temporo-parietal mass. There was no hepatosplenomegaly or lymphadenopathy and a chest $\mathrm{X}$-ray was normal. At craniotomy a hard encapsulated spherical mass, $4 \mathrm{~cm}$ in diameter, was removed. Histopathological examination once again showed a granulomatous mass made up of fibrous granulation tissue admixed with lymphocytes, plasma cells and macrophages (Figures 1 and 2). Gram stain for bacteria, Ziehl-Neilsen stain for mycobacteria, Levaditis' silver stain for treponemes, Warthin-Starry stain for the cat-scratch disease bacillus and stains for fungi failed to reveal any microorganisms. Immunohistological studies using monoclonal antibodies against Toxoplasma gondii and cytomegalovirus were negative. Electron microscopy of tissue samples (performed by Dr McPherson, E.M. Unit, John Radcliffe Hospital) failed to identify any organisms. Measurement of serum immunoglobulins at this stage revealed marked panhypogammaglobulinaemia 


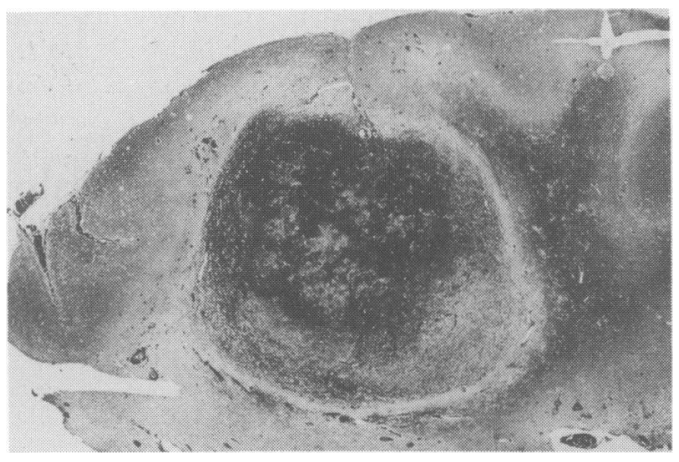

Figure 1 Low power view of a section through the discrete granuloma removed at the second operation (1984). Reticulin stain $(\times 5)$.

and further investigations confirmed the diagnosis of common variable immunodeficiency (Table I). Immunophenotyping of circulating lymphocytes revealed normal numbers of circulating $T$ and $B$ cells. Subsequent examination of her cerebrospinal fluid (CSF) did not reveal any significant abnormality. Syphillis serology was negative and a search for cytomegalovirus in CSF, urine and saliva was

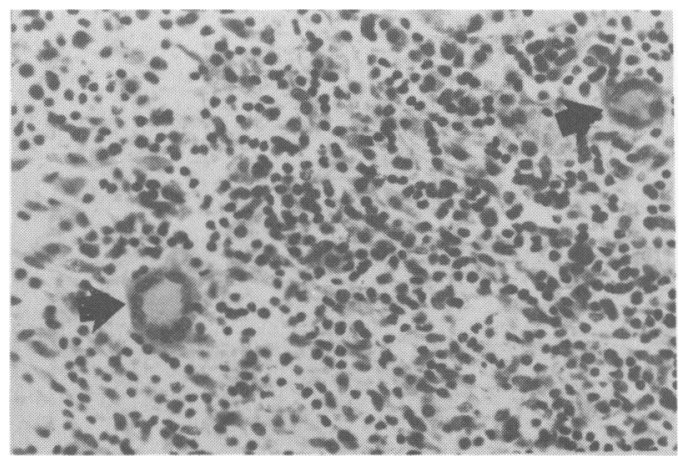

Figure 2 Higher power view of the inflammatory cell infiltrate in the granuloma. There are dense collections of lymphocytes and macrophages and scattered multinucleated giant cells (arrows). Haematoxylin and eosin stain $(\times 200)$.

unsuccessful. DNA hybridization studies on the patients' lymphocytes using a cDNA probe failed to reveal the human immunodeficiency virus antigen.

She has remained well since and is presently being followed-up regularly with cranial CT scans at 6-monthly intervals. She continues to remain

Table I Summary of investigations

\begin{tabular}{lll}
\hline Serum & & Normal range \\
\hline IgG & $0.8 \mathrm{~g} / 1$ & $6-13 \mathrm{~g} / 1$ \\
IgA & $0.2 \mathrm{~g} / \mathrm{l}$ & $0.8-3.0 \mathrm{~g} / \mathrm{l}$ \\
IgM & $0.3 \mathrm{~g} / 1$ & $0.4-2.5 \mathrm{~g} / 1$ \\
$\mathrm{C}_{3}$ & $102 \mathrm{mg} / \mathrm{dl}$ & $65-190 \mathrm{mg} / \mathrm{dl}$ \\
$\mathrm{C}_{4}$ & $21 \mathrm{mg} / \mathrm{dl}$ & $15-50 \mathrm{mg} / \mathrm{dl}$ \\
Calcium & $2.2 \mathrm{mmol} / 1$ & $2.1-2.6 \mathrm{mmol} / 1$ \\
Phosphate & $0.9 \mathrm{mmol} / \mathrm{l}$ & $0.8-1.4 \mathrm{mmol} / 1$ \\
Angiotensin converting enzyme & $62 \mathrm{IU} / 1$ & $21-54 \mathrm{IU} / 1$ \\
Electrophoresis & Hypogamma & \\
Isohaemagglutinins & Anti-A $<1: 4$ & \\
(Patient's blood group O) & Anti-B undetectable & \\
Serum antibodies to & & \\
Tetanus toxoid & & \\
Escherichia coli & Undetectable on repeated testing & \\
Diphtheria toxoid & & \\
Pneumococcus & & \\
Measles & $1: 2$ & \\
Herpes simplex & $<1: 2$ & \\
CMV & $<1: 2$ & \\
Rubella & $1: 10$ & \\
Salivary & & \\
IgA & Absent & \\
Secretory piece & Present & \\
Delayed typed hypersensitivity skin tests & & \\
Tuberculin & Negative & \\
Streptokinase-streptodornase & Negative & \\
Candida & Negative & \\
Dinitrochlorobenzene sensitization & Positive & \\
\hline
\end{tabular}


profoundly panhypogammaglobulinaemic but is surprisingly free of infection. After lengthy discussion with her family, immunoglobulin replacement therapy has not been instituted in view of her disinhibitory state.

\section{Discussion}

Common variable immunodeficiency is characterized by hypogammaglobulinaemia associated with varying degrees of defective T-cell and macrophage function. ${ }^{2-4}$ Most patients with CVI present with recurrent sino-pulmonary infection but a significant number go on to develop non-caseating granulomata, intestinal nodular lymphoid hyperplasia and/or splenomegaly. Despite their inability to produce antibodies against extrinsic antigens, about $10 \%$ of patients with CVI develop autoimmune problems such as immune thrombocytopenic purpura, neutropenia and Coombs' positive haemolytic anaemia, which in some patients may be the presenting feature. ${ }^{1}$

Granulomata are focal collections of inflammatory mononuclear cells consisting of macrophages, epithelioid cells, lymphocytes, plasma cells and giant cells. ${ }^{5}$ A granulomatous inflammatory response may be seen in a variety of disease states including infections (mycobacterial, treponemal, fungal, viral and helminthic), sarcoidosis and some of the vasculitides. ${ }^{6}$

In the context of primary immunodeficiency, granulomata have been described in chronic granulomatous disease and common variable immunodeficiency. ${ }^{1}$ It is thought in these cases that a sequestered antigen, probably a microorganism, triggers granuloma formation. In the acquired immunodeficiency syndrome (AIDS) cerebral granulomata are uncommon, but have been described in association with opportunistic taxoplasma and cryptococcal infection. ${ }^{7}$ More recently one of us (M.E.) has noted an unexplained brainstem granuloma in a haemophiliac male with acquired immunodeficiency syndrome which resulted in the 'locked-in' syndrome. In our patient the length of the history, lack of risk factors, absence of systemic infection, normal numbers of circulating CD4 positive lymphocytes and failure to demonstrate the HIV genome excludes the possibility of HIV infection.

It is interesting that patients with $\mathrm{X}$-linked agammaglobulinaemia do not develop granulomata in contrast to patients with CVI, in spite of experiencing recurrent infection. Antigen presenting cells (dendritic cells, macrophages) and $T$ helper cells play a pivotal role in granuloma formation and it is likely that impaired dendritic and $T$ helper cell function in patients with CVI leads to defective antigen processing with consequent granuloma formation. ${ }^{3,4}$ In contrast dendritic cell function is reportedly normal in patients with X-linked agammaglobulinaemia, although impaired $\mathrm{T}$ cell help has been noted. ${ }^{3}$

The presence of plasma cells in our patients' granulomas was highly unusual in view of her proven antibody deficiency. Plasma cells are usually absent or present in very small numbers in the granulomas associated with CVI, in keeping with the impaired $B$ cell maturation seen in this disease.

It is possible that phenytoin induced this patient's hypogammaglobulinaemia. Phenytoin was prescribed following her first craniotomy, over a 5 year period between 1974 and 1979. Phenytoin may induce reversible IgA deficiency in epileptic patients but reports of persistent hypogammaglobulinaemia are exceedingly rare. We are aware of only a single case report where phenytoin was implicated in the development of permanent panhypogammaglobulinaemia. ${ }^{8}$ Although we cannot rule out the possibility that phenytoin may have been instrumental in causing this patients' panhypogammaglobulinaemia, it is unlikely in view of the occurrence of the first cerebral granuloma before phenytoin was commenced, the lack of cutaneous hypersensitivity and the persistence of panhypogammaglobulinaemia 12 years after cessation of phenytoin therapy.

The presence of sarcoid-like granulomata in patients with CVI may in some cases obscure the definitive diagnosis of primary immunodeficiency. ${ }^{1}$ Although there have been a few reports of primary hypogammaglobulinaemia and Kveim-positive sarcoidosis, classical sarcoidosis is usually characterized by a polyclonal hypergammaglobulinaemia. ${ }^{9}$ Neurosarcoidosis has been known to present with intracranial space-occupying lesions due to granuloma formation ${ }^{10}$ and was considered as a possible diagnosis in this patient. However, a negative Kveim test, normal cerebrospinal fluid and plasma biochemistry, and a normal chest $\mathrm{X}$-ray rendered this unlikely.

In the presence of profound panhypogammaglobulinaemia, it would be reasonable to suggest that the granulomata in our patient were infective in origin, despite failure to demonstrate a microorganism. This diagnosis is much more likely than neoplasm to explain two separate masses occurring 10 years apart. The surprising absence of overt infection in this patient in the presence of marked antibody deficiency however remains unexplained. Our experience in this case prompts us to suggest that CVI should be included in the differential diagnosis of all cerebral granulomata. 


\section{Acknowledgements}

We wish to thank Dr David Webster, Northwick Park Hospital for the DNA hybridization studies and Mrs Angela Welby for her careful typing.

\section{References}

1. Asherson, G.L. \& Webster, A.D.B. Diagnosis and Treatment of Immunodeficiency Disease. Blackwell Scientific Publications, Edinburgh, 1980. p. 41.

2. Primary Immunodeficiency Diseases. Report of a World Health Organization sponsored meeting. Immuno Def Rev 1989, 1: 173-205.

3. Rozynska, K.E., Spickett, G.P., Millrain, M. et al. Accessory and $T$ cell defects in acquired and inherited hypogammaglobulinaemia. Clin Exp Immunol 1989, 78: 1-6.

4. Eibl, M.M., Mannhalter, J.W., Zlabinger, G. et al. Defective macrophage function in patients with common variable immunodeficiency. $N$ Engl J Med 1982, 307: 803-806.

5. Sheffield, E.A. The granulomatous inflammatory response (editorial). J Path 1990, 160: 1-2.
6. Sell, S. Immunology, Immunopathology and Immunity. Elsevier, New York, 1987, pp. 529-541.

7. Lechtenberg, R. \& Sher, J.H. AIDS in the Nervous System. Churchill Livingstone, New York, 1988, pp. 71-82.

8. Guerra, I.C., Fawcett, W.A., Redman, A.H. et al. Permanent intrinsic B cell immunodeficiency caused by phenytoin hypersensitivity. J Allergy Clin Immunol 1986, 77: 603-607.

9. Leen, C.L.S., Bath, J.C.J.L., Brettle, R.P. \& Yap, P.L. Sarcoidosis and primary hypogammaglobulinaemia: a report of two cases and a review of the literature. Sarcoidosis 1985, 2: 91-95.

10. Delaney, P. Neurologic manifestations in sarcoidosis. Ann Intern Med 1977, 87: 336-345. 